\title{
HighLIGHTS
}

\section{Physician reimbursement and bone mineral density testing}

In 2008, a change was made to the Ontario fee schedule for bone mineral density testing with dual-energy $\mathrm{x}$-ray absorptiometry (DXA). The new reimbursement policy was designed to restrict access to DXA testing among women at low risk of osteoporosis-related fracture. However, institution of new policies can sometimes have unexpected consequences. Jaglal and colleagues wondered if the policy would achieve its goal of promoting appropriate use of testing, with reduced use in women at low risk and increased use in women and men at higher risk.

In their analysis of data from health services databases from 2002 to 2011, the authors found that the overall number of DXA tests in Ontario increased from 2002 to 2008, and then began to decline after the policy was instituted (Figure 1 ). This change was mainly due to a decrease in the rate of testing among women at low risk (5.7 per 100 population in 2008/09 to 1.8 per 100 in 2010/2011.) However, reductions in DXA testing affected those at high risk of fracture as well. Rates of testing decreased in women over the age of 65 and in men and women at high risk because of a recent clinical fracture. CMAJ Open 2014;2:E45-E50

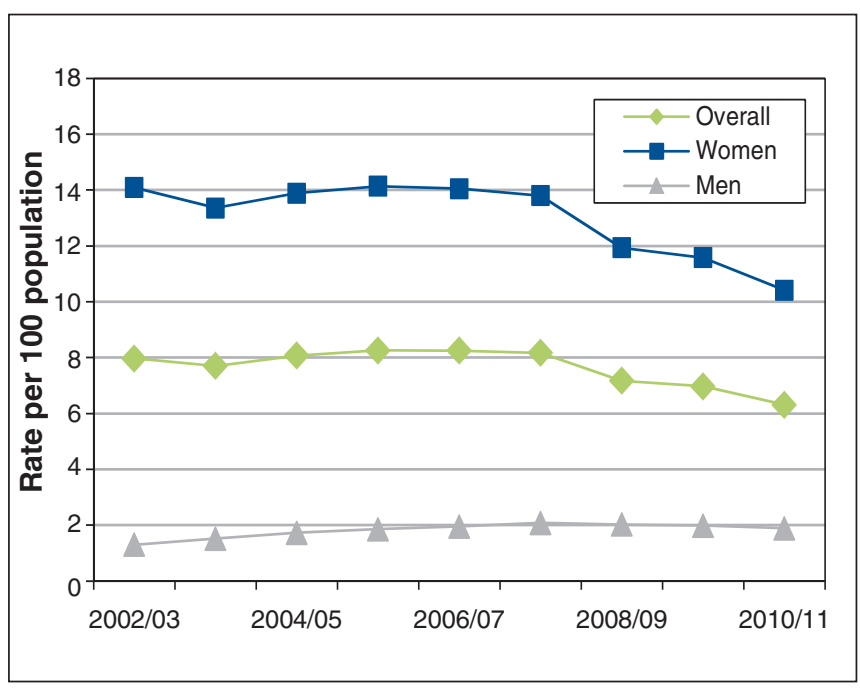

Figure 1: Age-standardized rates of dual-energy x-ray absorptiometry among women and men aged $68-70$ years not previously tested, $2002 / 03$ to $2010 / 11$.

\section{Geographic and facility-level variation in the use of peritoneal dialysis in Canada: a cohort study}

Every year, about 3000 patients will start some form of long-term dialysis therapy in Canada, and the number is increasing steadily. Peritoneal dialysis is associated with similar survival and improvements in quality of life compared with in-centre intermittent hemodialysis. Yet, only about $30 \%$ of patients requiring dialysis in Canada receive peritoneal dialysis.

In this retrospective cohort study, Sood and colleagues analyzed data from the Canadian Organ Replacement Register over a 10-year period to examine facility and geographic variation in the use of peritoneal dialysis. The study included 31778 patients, for whom peritoneal dialysis was the primary modality at 90 days after initiation, at 56 facilities in 13 geographic regions across Canada.

Use of peritoneal dialysis varied considerably across geographic regions (range $19.8 \%-36.1 \%$ ) (Table 1 ) and declined over the decade by $6 \%$ to $22.5 \%$ in 2010. The substantial differences the authors observed could not be explained by differences in patient case mix. After adjusting for case mix and facility-level quality indicators, $9.3 \%$ of the variability was attributable to facility factors and $3.4 \%$ to geographic factors. The authors suggest that this variability represents a possible area for improvement and may be amenable to health policy initiatives. CMAJ Open 2014;2:E36-E44

CMAJ 2014. DOI 10.1503/cmaj.140503

\begin{tabular}{|lc|}
\hline $\begin{array}{l}\text { Table 1: Adjusted odds ratios (with 95\% } \\
\text { confidence intervals) for use of peritoneal } \\
\text { dialysis at 90 days across geographic } \\
\text { regions of Canada. }\end{array}$ \\
\hline Region & Adjusted odds ratios \\
\hline Vancouver, BC & $1.51(1.33-1.73)$ \\
\hline Other, BC & $0.75(0.63-0.90)$ \\
\hline Eastern BC & $1.29(1.07-1.54)$ \\
\hline Northern AB & $0.70(0.60-0.81)$ \\
\hline Southern AB & $1.04(0.89-1.21)$ \\
\hline SK & $0.89(0.76-1.04)$ \\
\hline MB & Referent \\
\hline Northern ON & $0.95(0.81-1.11)$ \\
\hline Western ON & $0.75(0.67-0.85)$ \\
\hline Toronto, ON & $1.51(1.33-1.73)$ \\
\hline Eastern ON & $0.69(0.60-0.79)$ \\
\hline NS & $0.91(0.77-1.08)$ \\
\hline NB/NL/PEI & $0.72(0.62-0.85)$ \\
\hline
\end{tabular}

